\title{
Thermal Conductivity and Electrical Resistivity of Armco Iron
}

\author{
T. W. Watson, D. R. Flynn, and H. E. Robinson \\ Institute for Applied Technology, National Bureau of Standards, Washington, D.C. 20234
}

(August 22, 1967)

\begin{abstract}
New data are presented for the thermal conductivity and electrical resistivity of two samples of Armco iron. On a sample of material used in a round robin comparison between several laboratories, thermal conductivity was measured from -160 to $+640{ }^{\circ} \mathrm{C}$ and electrical resistivity was measured from -195 to $+1380^{\circ} \mathrm{C}$. On a sample of cold-worked Armco iron from a different lot, data are reported from -150 to $+200{ }^{\circ} \mathrm{C}$.

Key Words: Armco iron, conductivity, electrical conductivity, electrical resistivity, heat conductivity, heat transfer, iron, Lorenz function, resistivity, thermal conductivity.
\end{abstract}

\section{Introduction}

Commercially pure iron, usually produced by the American Rolling Mill Company and known as Armco iron, has been used for many years as a thermal conductivity reference material, either as a "heat flow meter" in the case of comparative thermal conductivity measurements or as a material to be used in checking apparatus in the case of absolute thermal conductivity measurements. Powell $[1]^{1}$ has reviewed the numerous published data available on the thermal conductivity of Armco iron and derived "most probable values," which he estimated to be good within \pm 2 percent from 0 to $600{ }^{\circ} \mathrm{C}$, and within about \pm 5 percent at $1000{ }^{\circ} \mathrm{C}$. The range of experimental values in the literature, however, is about 7 percent between 0 and $600{ }^{\circ} \mathrm{C}$, and increases to almost 30 percent at $1000{ }^{\circ} \mathrm{C}$. In an attempt to resolve this discordance of experimental results, C. F. Lucks of the Battelle Memorial Institute, Columbus Laboratories, proposed a round-robin of thermal conductivity measurements on Armco iron. The Battelle Memorial Institute (BMI) subsequently obtained a quantity of Armco iron and distributed samples to: National Physical Laboratory (NPL), Teddington, England; National Research Council (NRC), Ottawa, Canada; and National Bureau of Standards (NBS), Washington, D.C., and later to a number of other laboratories. Powell et al. [2], have reported the NPL measurements over the temperature range from -200 to $+1000{ }^{\circ} \mathrm{C}$; Laubitz has reported $[3,4]$ the NRC measurements from 30 to $1000{ }^{\circ} \mathrm{C}$.

The present paper reports thermal conductivity and electrical resistivity results obtained at the $\mathrm{Na}$ tional Bureau of Standards on the sample of Armco iron supplied to NBS by BMI. Thermal conductivity measurements were made at NBS over the temperature range -160 to $+640{ }^{\circ} \mathrm{C}$. Electrical resistivity

\footnotetext{
' Figures in brackets indicate the literature references at the end of this paper.
} See appendix for discussion of nonmetallic impurities. measurements were made over the temperature range -195 to $+1380{ }^{\circ} \mathrm{C}$.

\section{Sample Description}

The sample of Armco iron supplied to NBS by BMI was in the form of a round bar, nominally 1 in in diameter and $39 \mathrm{in}$ in length. The ends of this sample were stamped No. 3 and No. 4, the No. 3 end being immediately adjacent to the sample sent to NPL, and the No. 4 end adjacent to the sample sent to NRC. This Armco iron was stated to have been obtained from the Steel Sales Company, Chicago, Ill. The ladle analysis in weight percent, as given by the supplier, is as follows: C 0.02 , Mn 0.030 , P 0.006, S 0.023, Si 0.004, $\mathrm{Cu} 0.083, \mathrm{Fe}$ (by difference) 99.834. Powell [2] reported that an NPL analysis showed no significant variation from the analysis given above, other than the presence of 0.083 percent Ni. A spectrochemical analysis by the NBS Spectrochemistry Section yielded the following impurity content ${ }^{2}$ (in weight percent): $\mathrm{Mn}<0.1$, $\mathrm{Si}<0.015$, Cu 0.06, Ni 0.06, Cr 0.01, V $<0.01$, Mo $0.01, \mathrm{~W}<0.02$, Co $<0.01$, Ti 0.006, Sr 0.02, Nb $<0.01$, $\mathrm{Zr}<0.003$.

Battelle Memorial Institute reported that they had annealed the sample at $870^{\circ} \mathrm{C}$ for ${ }^{1 / 2} \mathrm{hr}$. The Rockwell hardness of the sample, as received, was found to vary between B30 and B50. A photomicrograph of this specimen, as viewed at $100 \mathrm{x}$, is shown in figure 1 . The specimen material exhibits large grains with no particular orientation.

\section{Thermal Conductivity Measurements}

The thermal conductivity measurements on the BMI Armco iron sample were made in the NBS metals apparatus which has been described by Ginnings [5] and by Watson and Robinson [6]. In brief, the measurement was made by determining the electrical power 


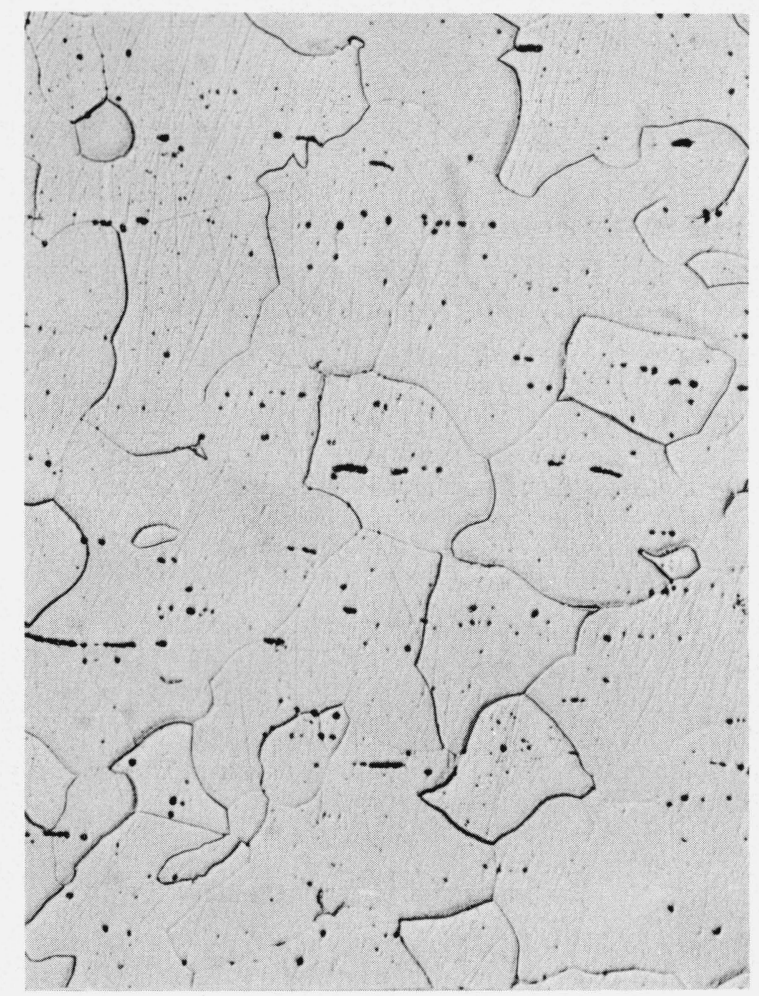

FigURE 1. Microstructure of the BMI Armco iron sample (X 100).

input to a heater in one end of a specimen $37.0 \mathrm{~cm}$ long and $2.386 \mathrm{~cm}$ in diameter, which was cooled at the other end by circulating water or liquid nitrogen. Temperatures were measured by means of thermocouples (fabricated from wire which had been calibrated by the NBS Temperature Physics Section) $3.51 \mathrm{~cm}$ apart, along the central portion of the bar, thus permitting the calculation of six thermal conductivity values, each at a different mean temperature, for each thermal equilibrium. A guard cylinder, concentric with the specimen, was used to minimize heat exchanges between the specimen and the surrounding insulation, and corrections were made for such heat exchanges.

TABLE 1. Test conditions for the thermal conductivity measurements

\begin{tabular}{ccccccc}
\hline \hline Series & $\begin{array}{c}\text { Appa- } \\
\text { ratus }\end{array}$ & $\begin{array}{c}\text { Heater } \\
\text { winding }\end{array}$ & Thermocouples & Insulation ${ }^{\text {a }}$ & $\begin{array}{c}\text { Atmos- } \\
\text { phere }\end{array}$ & $\begin{array}{c}\text { Number } \\
\text { of data } \\
\text { points }\end{array}$ \\
\hline 1 & A & Nichrome & $\begin{array}{c}\text { Chromel P: } \\
\text { alumel }\end{array}$ & $\begin{array}{c}\text { Diatomaceous } \\
\text { earth }\end{array}$ & Air & 12 \\
2 & B & Nichrome & $\begin{array}{c}\text { Platinum - } 10 \% \\
\text { rhodium : } \\
\text { platinum }\end{array}$ & $\begin{array}{c}\text { Powdered } \\
\text { alumina }\end{array}$ & Nitrogen & 18 \\
3 & B & $\begin{array}{c}\text { Pt-20\% } \\
\text { Rh }\end{array}$ & $\begin{array}{c}\text { Platinum-10\% } \\
\text { rhodium : } \\
\text { platinum }\end{array}$ & $\begin{array}{c}\text { Powdered } \\
\text { alumina }\end{array}$ & Vacuum & 18 \\
\hline
\end{tabular}

a Although diatomaceous earth is a better thermal insulation, it was necessary to use powdered alumina in series 2 and 3 in order to avoid contamination of the noble metal thermocouples.

${ }^{3}$ Note that none of the values of thermal conductivity and electrical resistivity given in this paper are corrected for the effect of thermal expansion of the specimen.
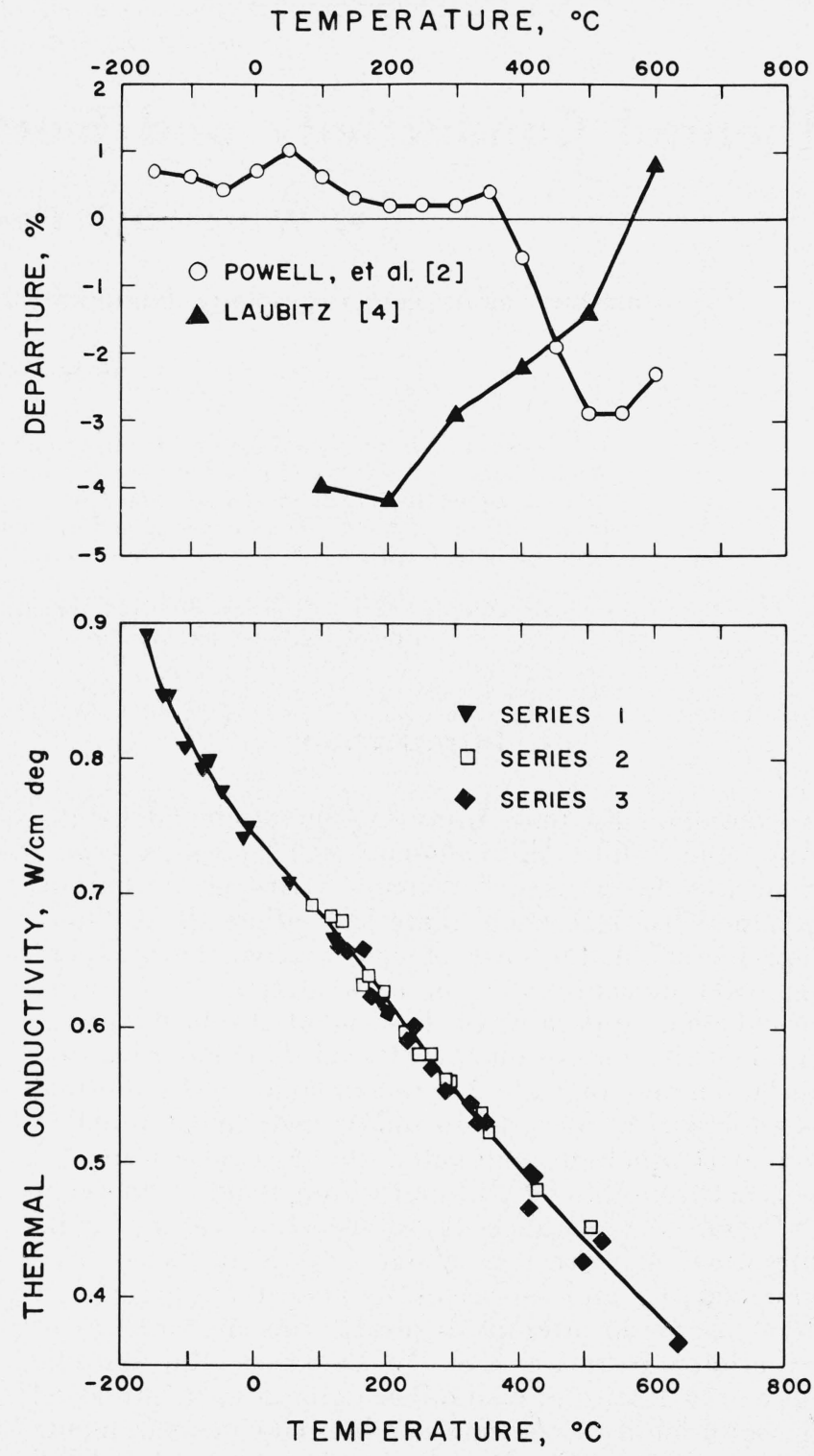

FigURE 2. The lower figure shows the data points obtained at NBS for the thermal conductivity of BMI Armco iron.

The three different symbols correspond to the different test conditions presented in table 1. The upper figure shows the percentage departures of the smoothed values of Powell et al. [2]. and of Laubitz [4] from the smooth curve in the lower figure.

Data were taken on the same sample in two different, but similar, apparatus with varying experimental conditions as indicated in table 1 . The smoothed NBS results ${ }^{3}$ which have not been corrected for thermal expansion, at $50{ }^{\circ} \mathrm{C}$ intervals are presented in table 2 (along with values for the electrical resistivity and the Lorenz function which will be discussed below). The curve in the lower drawing of figure 2 represents the thermal conductivity values given in table 2 ; the three different symbols represent data points corresponding to the three series of tests described in table 1 . For the material which we tested, in the state in which we tested it, the thermal conductivity values in table 2 
TABLE 2. Smoothed values for the thermal conductivity, electrical resistivity, and Lorenz function of BMI Armco iron

\begin{tabular}{|c|c|c|c|}
\hline $\begin{array}{l}\text { Tempera- } \\
\text { ture }\end{array}$ & $\begin{array}{c}\text { Thermal } \\
\text { conductivity }\end{array}$ & $\begin{array}{l}\text { Electrical } \\
\text { resistivity }\end{array}$ & $\begin{array}{l}\text { Lorenz } \\
\text { function }\end{array}$ \\
\hline $\begin{array}{c}{ }^{\circ} \mathrm{C} \\
-200\end{array}$ & $\begin{array}{l}W / \mathrm{cm} \text { deg } \\
\ldots \ldots \ldots \ldots \ldots \ldots\end{array}$ & $\begin{array}{c}\mu \Omega \mathrm{cm} \\
\mathrm{a} 1.5\end{array}$ & $V^{2} /$ deg $^{2}$ \\
\hline-160 & 0.887 & 2.8 & $2.16 \times 10^{-8}$ \\
\hline-150 & .873 & 3.1 & 2.20 \\
\hline-100 & .815 & 5.2 & 2.44 \\
\hline-50 & .775 & 7.4 & 2.58 \\
\hline 0 & .742 & 9.9 & 2.68 \\
\hline 50 & .712 & 12.6 & 2.77 \\
\hline 100 & .682 & 15.6 & 2.86 \\
\hline 150 & .652 & 19.0 & 2.92 \\
\hline 200 & .620 & 22.9 & 3.00 \\
\hline 250 & .587 & 27.2 & 3.05 \\
\hline 300 & .554 & 31.9 & 3.08 \\
\hline 350 & .523 & 37.0 & 3.10 \\
\hline 400 & .495 & 42.6 & 3.13 \\
\hline 450 & .469 & 48.7 & 3.16 \\
\hline 500 & .443 & 55.3 & 3.17 \\
\hline 550 & .417 & 62.4 & 3.16 \\
\hline 600 & .391 & 70.0 & 3.14 \\
\hline 640 & .371 & 76.6 & 3.11 \\
\hline 650 & & 78.3 & \\
\hline 700 & & 87.4 & \\
\hline 720 & & 91.3 & \\
\hline 740 & & 95.5 & \\
\hline 750 & & 97.9 & \\
\hline 760 & & 100.2 & \\
\hline 770 & & 102.8 & \\
\hline 780 & & 104.4 & \\
\hline 800 & & 106.5 & \\
\hline 850 & & 109.8 & \\
\hline 880 & & 111.5 & \\
\hline 900 & & 111.8 & \\
\hline 910 & & 112.2 & \\
\hline 920 & & 112.5 & \\
\hline 950 & & 113.6 & \\
\hline 1000 & & 115.2 & \\
\hline 1050 & & 116.8 & \\
\hline 1100 & & 118.2 & \\
\hline 1150 & & 119.5 & \\
\hline 1200 & & 120.8 & \\
\hline 1250 & & 121.9 & \\
\hline 1300 & 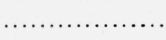 & 123.0 & \\
\hline 1350 & & 123.9 & \\
\hline 1380 & & 124.4 & \\
\hline
\end{tabular}

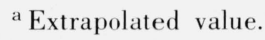

are estimated to be in error by not more than two percent.

In the upper drawing of figure 2, Powell's values [2] and Laubitz' adjusted values [4] for the thermal conductivity of BMI Armco iron are shown as percentage departures from the thermal conductivity values given in table 2 .

\section{Electrical Resistivity Measurements}

The electrical resistivity specimens were placed in series with a calibrated standard resistor and a regulated d-c power supply. The resistance of each specimen was determined by comparing the voltage drop across potential taps in the specimen with that
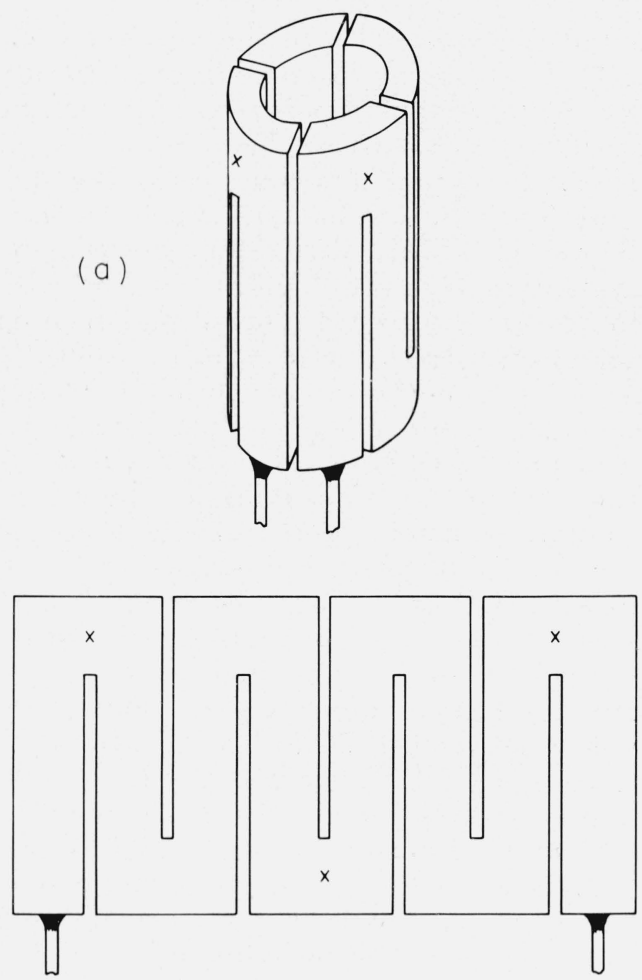

( b)

FIGURE 3. The upper sketch (a) shows the "squirrel-cage" specimen configuration used for the electrical resistivity measurements on BMI Armco iron.

The lower sketch (b) indicates the path of current flow.

across the standard resistor. In order to minimize thermoelectric effects, voltage drops in the specimens were measured with the current flowing normally and reversed. All voltage measurements were made using a precision d-c potentiometer.

The electrical resistivity at the ice point, $0{ }^{\circ} \mathrm{C}$, was determined by measuring the resistance between two knife edges $9.997 \mathrm{~cm}$ apart spanning the central portion of a $0.5003 \mathrm{~cm}$ diam bar machined from the thermal conductivity specimen described above.

The temperature-dependence of electrical resistivity was determined by measuring the electrical resistance of two different "squirrel-cage" specimens (see fig. 3) as functions of temperature. Three thermocouples peened into these specimens served to measure the temperature of the specimen during testing and also served as potential taps to measure the voltage drops in the specimen. Comparison of the ice-point resistance of these two specimens with the ice-point resistivity value separately determined on the $0.5003 \mathrm{~cm}$ diam bar enabled calculation of resistivity values as functions of temperature.

The first squirrel-cage specimen of BMI Armco iron was fabricated from the end of the NBS thermal conductivity specimen which had not been heated during testing. Data were taken in air in an isothermal cryostat from -195 to $+75{ }^{\circ} \mathrm{C}$ with $\mathrm{Chromel} \mathrm{P}$ versus 
constantan thermocouples in the specimen and from 0 to $1380{ }^{\circ} \mathrm{C}$ in helium in an isothermal furnace with platinum -10 percent rhodium versus platinum and also platinum - 30 percent rhodium versus platinum -6 percent rhodium thermocouples in the specimen. Data were first taken on heating to $850{ }^{\circ} \mathrm{C}$. On cooling back down, the electrical resistance of the specimen at room temperature was found to be lower by about $0.1 \mu \Omega \mathrm{cm}$, or 1 percent. On second heating, data were taken from room temperature to $1380{ }^{\circ} \mathrm{C}$. Since Powell [2] had reported a change in the resistivity at $910{ }^{\circ} \mathrm{C}$, corresponding to the alpha-gamma transformation in iron, data were taken at about 2-deg intervals from 900 to $920{ }^{\circ} \mathrm{C}$, looking for the effect of the alpha-gamma transformation. No effect was foundthe precision of the data was such that a change of 0.1 percent could easily have been detected. Study of a large scale plot of the data indicated that the electrical resistivity of the iron had undergone a drop, estimated by extrapolation as about one-half percent, somewhere between 875 and $900{ }^{\circ} \mathrm{C} .{ }^{+}$Data taken on cooling from $1380{ }^{\circ} \mathrm{C}$ indicated a jump in electrical resistivity of perhaps two-tenths of 1 percent between 895 and $890{ }^{\circ} \mathrm{C}$. After cooling from $1380{ }^{\circ} \mathrm{C}$, the electrical resistance of the specimen at the ice-point was about three percent lower than the original resistance before the specimen had been heated.

The second squirrel-cage specimen was fabricated from an unused portion of the stock supplied to NBS by BMI, annealed in helium at $850{ }^{\circ} \mathrm{C}$ for about $1 / 2$ hr to relieve possible strain introduced during fabrication, and then cooled to room temperature. Data were taken from $-195 \cdot$ to $+50{ }^{\circ} \mathrm{C}$ in air with copper versus constantan thermocouples in the specimen and from 0 to $850{ }^{\circ} \mathrm{C}$ in helium with platinum -10 percent rhodium versus platinum thermocouples in the specimen. These data were taken in the following order: on heating at $50 \mathrm{deg}$ intervals to $700{ }^{\circ} \mathrm{C}$, on heating at approximately $1 \mathrm{deg}$ intervals from 745 to $770{ }^{\circ} \mathrm{C}$, on cooling at approximately $0.5 \mathrm{deg}$ intervals from 763 to $7499^{\circ} \mathrm{C}$, on heating at 800 and $8500^{\circ} \mathrm{C}$, on cooling at 100 deg intervals from 800 to $0{ }^{\circ} \mathrm{C}$. A slight hysteresis $(<0.2 \%)$ was found between 754 and $761{ }^{\circ} \mathrm{C}$, presumably corresponding to the Curie transformation. The ice-point resistance of the sample was found to be 0.7 percent less than it had been at the beginning of testing.

The electrical resistivity values given in table 2 were obtained by combining and smoothing the data obtained on first heating of the specimens. No corrections were made for thermal expansion. For the material which we tested, in the state in which we tested it, the resistivity values tabulated are estimated to be in error by not more than 2 percent, or $0.1 \mu \Omega \mathrm{cm}$, whichever is greater. Most of this estimated uncertainty arises from the vagaries of this material, rather than from experimental error. All electrical resistance

\footnotetext{
+ Since our measurements were made, Fulkerson, Moore, and McElroy [7] reported that their electrical resistivity measurements on BMI Armeo iron indicated that the alphagamma transformation was between 893 and $898^{\circ} \mathrm{C}$
}
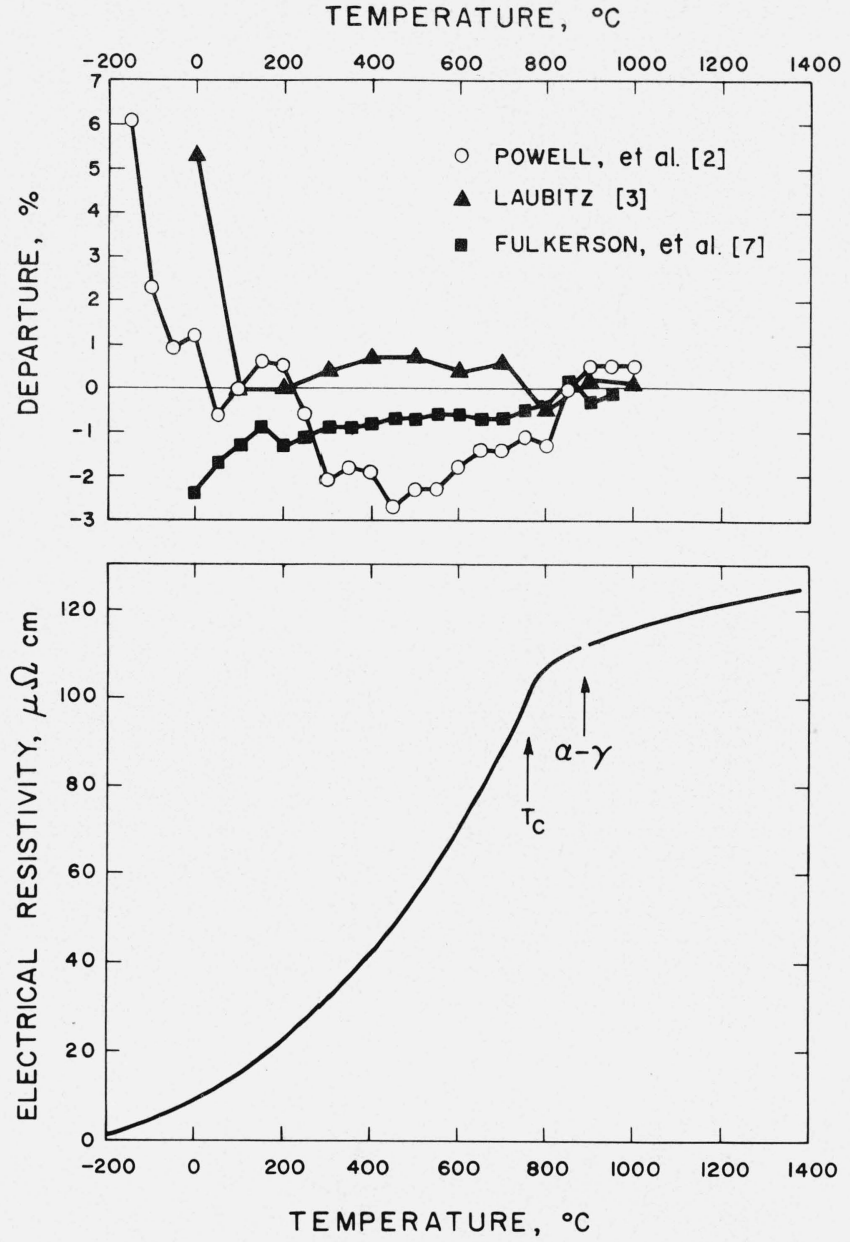

FIGURE 4. The lower figure represents the data obtained at NBS for the electrical resistivity of BMI Armco iron on first heating of a specimen which previously had been annealed at $850{ }^{\circ} \mathrm{C}$ for $1 / 2 h r$.

The upper figure shows the percentage departures of the smoothed values of Powell et al. [2]. Laubitz |3], and Fulkerson et al. [7]. from the curve in the lower figure.

measurements are believed to have been accurate to \pm 0.1 percent or better. The mean temperature of the sample is believed to have been known within \pm 3 deg below $1100{ }^{\circ} \mathrm{C}$ and within $\pm 5 \mathrm{deg}$ at $1380^{\circ} \mathrm{C}$. The uncertainty in resistivity directly attributable to the uncertainty in mean temperature would be about 0.8 percent just below the Curie point and would be less at all other temperatures.

The curve in the lower drawing of figure 4 represents the electrical resistivity values given in table 2 . The location of the Curie temperature is indicated by the arrow labeled $T_{c}$; the break in the curve corresponding to the alpha-gamma transformation is indicated by the arrow labeled $\alpha-\gamma$. In the upper drawing of figure 4, the values of Powell [2], Laubitz [3], and Fulkerson, Moore, and McElroy [7] for the electrical resistivity of BMI Armco iron are shown as percentage departures from our values as given in table 2. 


\section{Lorenz Function}

The values obtained for the Lorenz function, $\lambda \rho / T$ (where $\lambda$ is thermal conductivity, $\rho$ is electrical resistivity, and $T$ is absolute temperature), are given in table 2. The curve in the lower drawing of figure 5 represents these values. In the upper drawing of figure 5, Powell's values [2| and Laubitz' values, which we have computed from his electrical resistivity values as reported in $[3 \mid$ and his revised thermal conductivity values as reported in [4], for the Lorenz function of BMI Armco iron are shown as percentage departures from the values given in table 2 .

\section{Comments}

C. F. Lucks of the Battelle Memorial Institute is preparing a paper in which he will discuss in detail the results of the round-robin thermal conductivity measurements on BMI Armco iron. In addition to the results reported in this paper, and those of Powell [2] and of Laubitz $[3,4]$ which have been published pre-
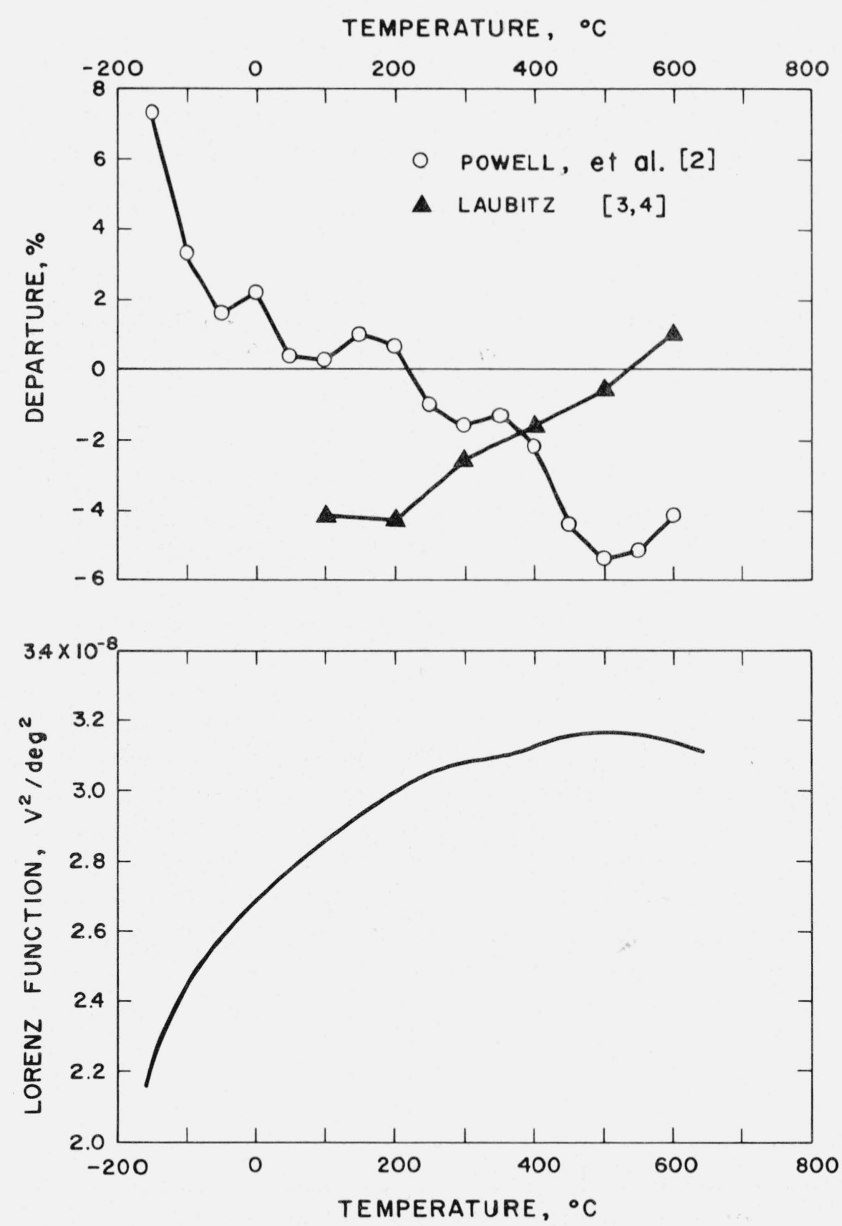

FIGURE 5. The lower figure represents the data obtained at NBS for the Lorenz function of BMI Armco iron.

The upper figure shows the percentage departure of the smoothed values of Powell et al. $[2]$. and Laubitz $\mid 3,4]$ from the curve in the lower figure. viously, Lucks will discuss other unpublished results from other laboratories. In view of this, the authors feel there is no need to discuss the above data beyond what has been done.

Powell [1] has summarized thermal conductivity measurements on Armco iron made through the year 1960. Powell, Ho, and Liley [8] presented a compendium of essentially all of the known thermal conductivity data on Armco iron and also on pure iron through the year 1965. After the present paper was written, Shanks, Klein, and Danielson [11] have published values for the thermal diffusivity, specific heat, and electrical resistivity of BMI Armco iron.

In the appendix, some previously unpublished data on another sample of Armco iron, not from the BMI lot, are presented.

\section{Appendix}

Measurements over the temperature range from -160 to $+200{ }^{\circ} \mathrm{C}$ were made of the thermal conductivity and electrical resistivity of a sample of Armco iron submitted by U.S. Army Missile Support Command, U.S. Army Missile Command, Redstone Arsenal, Alabama. A spectrochemical analysis by the NBS Spectrochemistry Section yielded the following impurity content (in weight percent): $\mathrm{Mn}<0.1$, $\mathrm{Si}<0.015, \mathrm{Cu} 0.03, \mathrm{Ni} 0.04, \mathrm{Cr} 0.01, \mathrm{~V}<0.01, \mathrm{Mo}$ $0.01, \mathrm{~W}<0.02$, Co $<0.01$, Ti 0.006 , Sr 0.02 , Nb $<0.01$, $\mathrm{Zr}<0.003$. The Rockwell B hardness of this sample, as received, was found to be 72 . A photograph of this specimen, as viewed at $100 \mathrm{X}$, is shown in figure 6 .

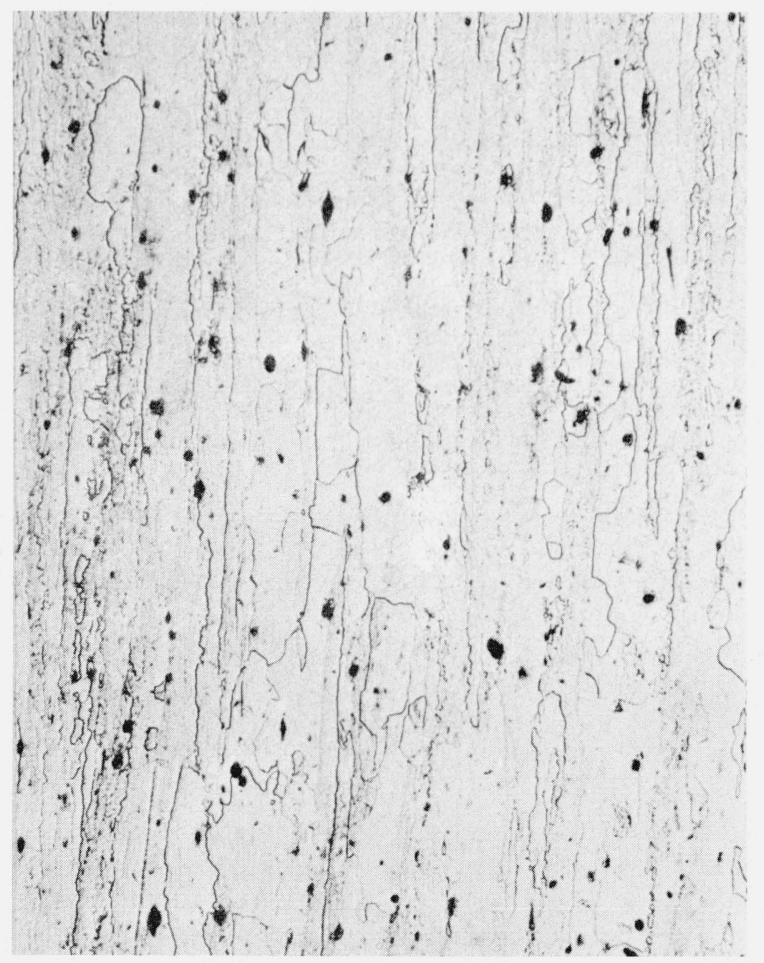

Figure 6. Microstructure of the cold-worked Redstone Arsenal sample of Armco iron (X 100). 
This material exhibits an oriented microstructure typical of a cold-worked material, with the long directions of the grains parallel to the long axis of the specimen.

The thermal conductivity measurements were made using the equipment designated as Apparatus A in table 1 .

For this specimen, electrical resistivity measurements were made in the thermal conductivity apparatus at the temperature conditions existing at the end of each pair of runs for determining the thermal conductivity, by passing a direct current along the bar. Observations were made of the potentials between the Chromel $\mathrm{P}$ and/or Alumel leads of the span thermocouples, with the current direction forward and reversed. Due to a slight warming of the bar during the period of current flow, the average resistivity for a span was assigned to correspond to the time-average of the span mean temperature over this period. A separate measurement on the same specimen was carried out in an ice bath using the thermocouple leads as potential taps.

TABLE 3. Thermal conductivity, electrical resistivity, and Lorenz function of the Redstone Arsenal sample of Armco iron

\begin{tabular}{c|c|c|c}
\hline \hline Temperature & $\begin{array}{c}\text { Thermal } \\
\text { conductivity }\end{array}$ & $\begin{array}{c}\text { Electrical } \\
\text { resistivity }\end{array}$ & $\begin{array}{c}\text { Lorenz } \\
\text { function }\end{array}$ \\
\hline & $W / \mathrm{cm} \mathrm{deg}$ & $\mu \Omega \mathrm{cm}$ & $V^{2} / \mathrm{deg}^{2}$ \\
${ }^{\circ} \mathrm{C}$ & 0.903 & 2.9 & $2.11 \times 10^{-8}$ \\
-150 & .844 & 4.7 & 2.30 \\
-100 & .795 & 6.9 & 2.45 \\
-50 & .754 & 9.4 & 2.59 \\
0 & .720 & 12.2 & 2.71 \\
50 & .687 & 15.3 & 2.82 \\
100 & .655 & 18.8 & 2.90 \\
150 & .620 & 22.5 & 2.95 \\
200 & & &
\end{tabular}

The values obtained for the thermal conductivity, electrical resistivity, and Lorenz function of the Redstone Arsenal sample of Armco iron are given in table 3 for the temperature range -160 to $+200{ }^{\circ} \mathrm{C}$. These values are shown in figure 7 as percent departures from the values given in table 2 for the BMI iron.

In general, cold-working raises the electrical resistivity and lowers the thermal conductivity of a given material, the effect on thermal conductivity increasing at lower temperatures (see, for example, the work of White [9] on gold, silver, and copper). Thus, on the basis of the cold-worked state versus the annealed state only, assuming identical chemical composition, the thermal conductivity of the Redstone Arsenal specimen would be expected to be lower than that of the BMI specimen rather than higher, as was found. The electrical resistivity of the Redstone Arsenal specimen was significantly lower than that of the BMI specimen (which had an ice-point resistivity of 9.88 $\mu \Omega \mathrm{cm}$ as compared to $9.36 \mu \Omega \mathrm{cm}$ for the Redstone Arsenal specimen), implying greater purity of the Redstone Arsenal specimen, and confirming the finding of a higher thermal conductivity for it than for the BMI specimen.

Godfrey et al. [10], report (pp. 26-29) that a quantitative chemical analysis showed the presence of 0.086
TEMPERATURE, ${ }^{\circ} \mathrm{C}$
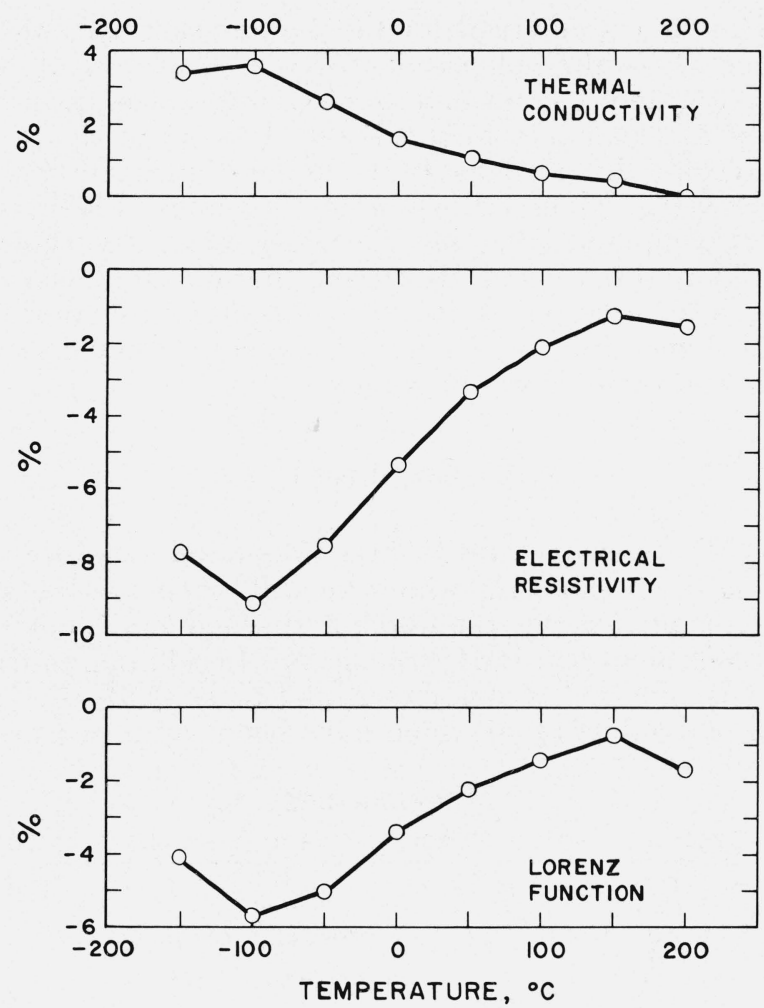

FIGURE 7. Percentage departures of the values obtained for the thermal conductivity, electrical resistivity, and Lorenz function of the Redstone Arsenal sample of Armco iron from the corresponding values obtained for the BMI sample.

percent $\mathrm{O}_{2}, 0.023$ percent $\mathrm{S}$, and 0.013 percent $\mathrm{C}$ (all weight percentages) in an Armco iron sample which they investigated. They report the presence, in this sample, of about 0.9 volume percent of a second phase, presumed to consist of oxides, sulfides, and phosphides. On a sample of BMI Armco iron, they found 1.3 volume percent of a second phase. The amount of nonmetallic impurities in a sample of Armco iron and, as pointed out by Godfrey et al. (p. 40), also the physical state of the impurities, may be of quite significant importance as regards the thermal and electrical conductivities. Impurities in solution would be expected to have a much greater effect on thermal and electrical conductivity than would impurities present as a dispersed second phase.

A significant difference in purity between the Redstone Arsenal specimen and the BMI specimen could only be explicitly determined by a more complete chemical analysis of both specimens, including quantitative analysis for nonmetallic impurities. A detailed microstructural analysis would also be required to determine the physical state of the impurities present. It is interesting whether the orientation of the microstructure in the cold-worked specimen would result in anisotropy in the electrical and thermal conductivities of the metal in its present state. 


\section{References}

[1] R. W. Powell, Armco iron as a thermal conductivity standard: review of published data, in Progress in International Research on Thermodynamics and Transport Properties, p. 454 (ASME, Academic Press, New York, 1962).

[2] R. W. Powell, M. J. Hickman, R. P. Tye, Miss M. J. Woodman, Armco iron as a thermal conductivity standard: new determinations at the National Physical Laboratory, ibid, p. 466.

[3] M. J. Laubitz, Thermal and electrical properties of Armco iron at high temperatures, Can. J. Phys. 38, 887 (1960).

[4] M. J. Laubitz, The unmatched guard method of measuring thermal conductivity at high temperatures, Can. J. Phys. 41, 1663 (1963).

[5] D. C. Ginnings, Standards of heat capacity and thermal conductivity, in Thermoelectricity, edited by Paul H. Egli, p. 320 (Wiley, New York and London, 1960).

[6] T. W. Watson and H. E. Robinson, Thermal conductivity of some commercial iron-nickel alloys, Trans. ASME J. Heat Transfer 83C, 403 (1961).
[7] W. Fulkerson, J. P. Moore, and D. L. McElroy, Comparison of the thermal conductivity, electrical resistivity, and Seebeck coefficient of a high-purity iron and an Armco iron to $1000{ }^{\circ} \mathrm{C}$, J. Appl. Phys. 37, 2639 (1966).

[8] R. W. Powell, C. Y. Ho, and P. E. Liley, Thermal conductivity of selected materials, NSRDS-NBS 8 (1966).

[9] G. K. White, The thermal conductivity of gold at low temperatures, Proc. Phys. Soc. (London) A66, 559 (1953).

G. K. White, The thermal conductivity of silver at low temperatures, Proc. Phys. Soc (London) A66, 844 (1953).

G. K. White, The thermal and electrical conductivity of copper at low temperatures, Aust. J. Physics 6, 397 (1953).

[10] T. G. Godfrey, W. Fulkerson, T. G. Kollie, J. P. Moore, and D. L. McElroy, Thermal conductivity of uranium dioxide and Armco iron by an improved radial heat flow technique, ORNL-3556 (June 1964).

[11] H. R. Shanks, A. H. Klein, and G. C. Danielson, Thermal properties of Armco iron, J. Appl. Phys. 38, 2885 (1967).

(Paper 71C4-259) 